\title{
Tracheal Tube Design and Ventilator-Associated Pneumonia
}

\author{
Anahita Rouzé MD, Emmanuelle Jaillette MD, Julien Poissy MD PhD, Sébastien Préau MD PhD, \\ and Saad Nseir MD PhD
}

\author{
Introduction \\ Subglottic Secretion Drainage \\ Continuous Control of Cuff Pressure \\ Polyurethane-Cuffed Tracheal Tubes \\ Tapered-Cuff Tracheal Tubes \\ Silver-Coated Tracheal Tubes \\ Low-Volume Low-Pressure Cuffs \\ Summary
}

\begin{abstract}
Microaspiration of contaminated oropharyngeal and gastric secretions is the main mechanism for ventilator-associated pneumonia (VAP) in critically ill patients. Improving the performance of tracheal tubes in reducing microaspiration is one potential means to prevent VAP. The aim of this narrative review is to discuss recent findings on the impact of tracheal tube design on VAP prevention. Several randomized controlled studies have reported that subglottic secretion drainage (SSD) is efficient in VAP prevention. Meta-analyses have reported conflicting results regarding the impact of SSD on duration of mechanical ventilation, and one animal study raised concern about SSD-related tracheal lesions. However, this measure appears to be cost-effective. Therefore, SSD should probably be used in all patients with expected duration of mechanical ventilation $>48 \mathrm{~h}$. Three randomized controlled trials have shown that tapered-cuff tracheal tubes are not useful to prevent VAP and should probably not be used in critically ill patients. Further studies are required to confirm the promising effects of continuous control of cuff pressure, polyurethane-cuffed, silvercoated, and low-volume low-pressure tracheal tubes. There is moderate evidence for the use of SSD and strong evidence against the use of tapered-cuff tracheal tubes in critically ill patients for VAP prevention. However, more data on the safety and cost-effectiveness of these measures are needed. Other tracheal tube-related preventive measures require further investigation. Key words: tracheal tube; endotracheal tube; cuff; tapered; conical; polyurethane; subglottic secretion drainage; PneuX; silver-coated; continuous control; pressure; pneumonia; infection. [Respir Care 2017;62(10):1316-1323.

(C) 2017 Daedalus Enterprises]
\end{abstract}

\section{Introduction}

Despite substantial improvement in the understanding of ventilator-associated pneumonia (VAP) pathogenesis

The authors are affiliated with the Centre de Réanimation, CHU Lille, Lille, France. Drs Poissy and Nseir are also affiliated with the Faculté de Médecine, University of Lille, Lille, France. and prevention during the last few decades, this infection is still common in critically ill patients. Its incidence is higher in developing countries and in Europe than in the United States $(22,14.4$, and 2.8 VAP episodes/1,000 mechanical ventilation days, respectively). ${ }^{1-3}$ However, a re-

\footnotetext{
Dr Nseir has disclosed relationships with Medtronic, MSD, Ciel Medical, and Bayer. The other authors have disclosed no conflicts of interest.
} 


\section{Tracheal Tube Design and VAP}

cent study questioned the VAP rates reported to the Centers for Disease Control and Prevention National Healthcare Safety Network and reported higher and stable rates of VAP (10\%) in the United States, based on the data of the Medicare Patient Safety Monitoring System. ${ }^{4}$

VAP is associated with increased mortality and morbidity. Although the impact of VAP on mortality is still a matter for debate, its negative impact on duration of mechanical ventilation, length of ICU stay, and cost was repeatedly reported in several studies.., 6

Microaspiration of contaminated secretions around the tracheal cuff is the main mechanism for entry of bacteria into the lower respiratory tract. ${ }^{7}$ Tracheobronchial colonization, resulting from microaspiration, could progress to ventilator-associated tracheobronchitis or pneumonia, depending on the quantity and virulence of aspirated bacteria and defense mechanisms. ${ }^{8,9}$ Improving the design of tracheal tubes is a key issue in the prevention of microaspiration and VAP. ${ }^{10}$ The aim of this narrative review is to discuss recent clinical findings on the relationship between tracheal tube design and the incidence of VAP in critically ill patients.

Data for this review were identified through searches of PubMed and from bibliographies of relevant articles. We undertook a comprehensive search in PubMed, from December 1996 through December 2016, using the terms "tracheal tube AND pneumonia," "endotracheal tube AND pneumonia," "tracheal cuff AND pneumonia," and "endotracheal cuff AND pneumonia." The search was limited to publications in English.

Clinical studies were selected for this review if they reported on the relation between tracheal tube design and pneumonia in ICU subjects. All abstracts were reviewed by 2 independent reviewers (AR and $\mathrm{SN}$ ). Articles of relevant abstracts were reviewed by the authors and included in this review. A summary of selected studies is given in Table 1.

\section{Subglottic Secretion Drainage}

Subglottic secretion drainage (SSD) is the most frequently studied measure for VAP prevention. At least 20 randomized controlled trials and 6 meta-analyses were conducted to determine the efficiency of this measure in reducing VAP incidence. A recent meta-analysis of 17 randomized controlled trials, with 3,369 subjects, found significant reduction of VAP incidence in subjects with SSD, compared with controls (risk ratio $0.58,95 \%$ CI

Correspondence: Saad Nseir MD PhD, CHU Lille, Centre de Réanimation, F-59000 Lille, France. E-mail: s-nseir@chru-lille.fr.

DOI: $10.4187 /$ respcare. 05492
0.51-0.67, $\left.\mathrm{I}^{2}=0 \%\right) .{ }^{11}$ However, no significant impact was found on duration of mechanical ventilation, ICU stay, or mortality. A more recent meta-analysis, ${ }^{12}$ including 3 additional randomized controlled trials with 3,544 subjects, reported similar results on efficiency. SSD was associated with reduction of VAP incidence in 4 high-quality trials (risk ratio $0.54,95 \%$ CI $0.40-0.74, P<.001$, $\mathrm{I}^{2}=0 \%$ ) and in all trials (risk ratio $=0.55,95 \% \mathrm{CI} 0.48-$ $\left.0.63, P<.001, \mathrm{I}^{2}=0 \%\right)$. SSD also significantly reduced the duration of mechanical ventilation (risk ratio $=-1.17 \mathrm{~d}$, $\mathrm{CI}-2.28$ to $-0.06 \mathrm{~d}, P=.006)$. However, heterogeneity was apparent $\left(\mathrm{I}^{2}=54 \%\right)$ in SSD effect size across trials. Another study also showed that SSD might be helpful to reduce antibiotic use in the ICU.13

To evaluate the cost-effectiveness of SSD, Shorr and O'Malley ${ }^{14}$ used a decision model with reduction of VAP prevalence, among subjects requiring $>72 \mathrm{~h}$ of mechanical ventilation, as the primary outcome. Assuming a baseline $25 \%$ prevalence of VAP along with a $30 \%$ relative reduction in the SSD group, a nearly $\$ 5,000$ savings per case of prevented VAP was reported, despite a substantially higher acquisition cost for the SSD tracheal tube. Hallais et al ${ }^{15}$ performed a cost/benefit analysis, based on hypothetical replacement of conventional ventilation by continuous SSD. They reported that assuming a VAP cost of $€ 4,387$, a total of 3 averted VAP episodes would neutralize the additional cost and that continuous SSD was cost-effective even when assuming the most pessimistic scenario of VAP incidence and cost. More recently, BranchElliman et $\mathrm{al}^{16}$ performed a cost/benefit decision model and constructed a Markov model to determine the preferred VAP prevention strategy. They suggested that the use of SSD and probiotics was cost-effective for VAP prevention.

An animal study raised concern regarding the possible tracheal ischemic lesions related to SSD. ${ }^{17}$ In addition, a case series of 6 patients reported that automated intermittent subglottic aspiration may result in significant and potential harmful invagination of tracheal mucosa into the suction lumen. ${ }^{18}$ However, SSD is widely used in Europe, and no significant concern about adverse effects was reported. Further, a large randomized controlled multi-center trial reported similar rates of postextubation laryngeal dyspnea in subjects with SSD, as compared with controls. ${ }^{19}$

Although SSD is recommended (moderate level of evidence) by the 2014 Infectious Disease Society of America/Society for Healthcare Epidemiology of America guidelines on VAP prevention, ${ }^{20}$ further studies are required to better evaluate the cost-effectiveness of this preventive measure and its safety. In routine practice, the major limitation for using SSD is the fact that many patients are intubated before ICU admission with tracheal tubes with no additional channel for SSD. A new device allowing 


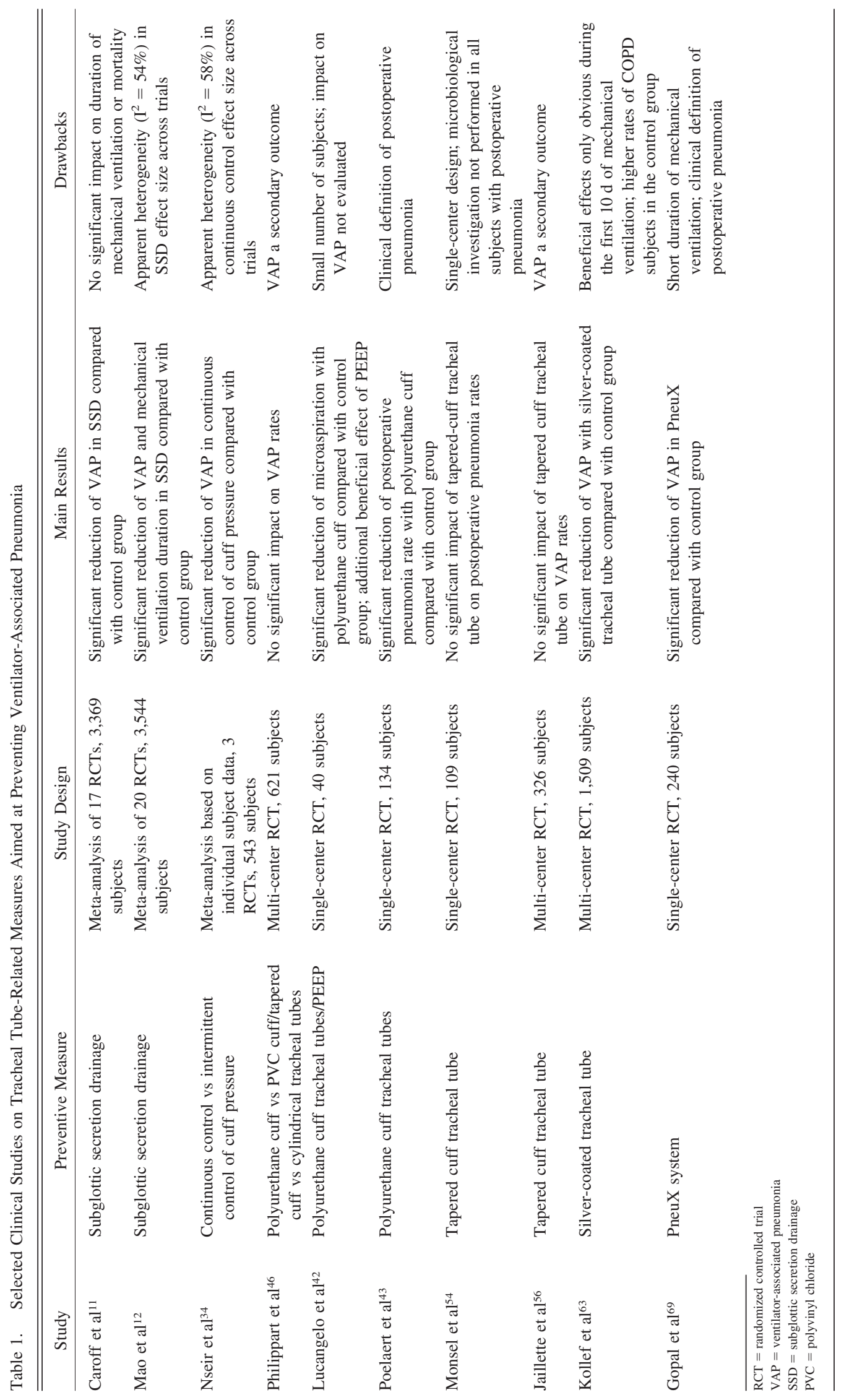


performance of SSD in patients intubated with standard tracheal tubes has been developed and commercialized in the United States. ${ }^{21}$ However, further clinical evaluation is required to determine its efficiency in drainage of subglottic secretions and VAP prevention. SSD is an interesting preventive measure in patients requiring invasive mechanical ventilation $>48 \mathrm{~h}$, but identifying these patients before intubation could be a difficult task. To overcome this difficulty, some authors have evaluated the efficiency of SSD in all patients requiring intubation. ${ }^{22}$ However, the cost-effectiveness would probably be better in targeted patients with expected duration of mechanical ventilation $>48 \mathrm{~h}$. Although physicians could sometimes easily identify these patients, better predictive scores should be developed to accurately select this population.

\section{Continuous Control of Cuff Pressure}

Underinflation of tracheal cuff was identified as a risk factor for VAP by an observational study. ${ }^{23}$ Despite intermittent control of cuff pressure $\left(\mathrm{P}_{\text {cuff }}\right)$, using a manometer, intubated critically ill subjects spend a large amount of time with underinflation $\left(<20 \mathrm{~cm} \mathrm{H}_{2} \mathrm{O}\right)$ or overinflation $\left(>30 \mathrm{~cm} \mathrm{H}_{2} \mathrm{O}\right.$ ) of $\mathrm{P}_{\text {cuff }} \cdot{ }^{24}$ Underinflation and overinflation of $\mathrm{P}_{\text {cuff }}$ were identified as risk factors for short-term complications, such as microaspiration of contaminated secretions, VAP, and tracheal ischemic lesions. ${ }^{25}$ Several devices aiming at continuously controlling $\mathrm{P}_{\text {cuff }}$ are available, ${ }^{26-29}$ but few of them have been validated by clinical studies. ${ }^{26,30,31}$

Two randomized controlled trials were conducted to determine the impact of continuous control of $\mathrm{P}_{\text {cuff }}$ on intubation-related complications. ${ }^{30,32}$ The study conducted by Valencia et al ${ }^{32}$ did not show any significant impact of continuous control of $\mathrm{P}_{\text {cuff }}$ on VAP incidence. The subsequent study, conducted by our group, ${ }^{30}$ found a significant reduction in abundant microaspiration of gastric contents and a substantial decrease in VAP rate $(62 \%)$ in subjects who received continuous control of $\mathrm{P}_{\text {cuff }}$, compared with the control group. However, no significant impact was found on tracheal ischemic lesions. Several factors might explain the different results of these trials, including the difference in devices used for $\mathrm{P}_{\text {cuff }}$ control, study population, and VAP rate in the control group.

In 2014, a quasi-randomized controlled study was conducted to determine the impact of continuous control of $\mathrm{P}_{\text {cuff }}$, using an electronic device, on VAP incidence in critically ill subjects. ${ }^{33}$ The authors reported a significant reduction $(51 \%)$ in VAP rate in subjects who received continuous control of $\mathrm{P}_{\text {cuff }}$, compared with those who received routine care with a manometer.

A meta-analysis of the individual data of subjects $(n=543)$ included in the 3 above-discussed single-center trials was performed. ${ }^{34}$ Thirty-six cases of VAP (13.6\%) were diagnosed in the continuous control group, and 72
(25.7\%) were diagnosed in the routine care group (hazard ratio $0.47,95 \%$ CI $0.31-0.71, P<.001)$. However, heterogeneity was apparent in continuous control effect size across trials $\left(\mathrm{I}^{2}=58 \%, P=.09\right)$. The number of patients needed to treat to prevent one VAP episode was 8 . No significant impact of continuous control of $\mathrm{P}_{\text {cuff }}$ was found on duration of mechanical ventilation, ICU stay, or mortality.

Further large multi-center studies are required to confirm the impact of continuous control of $\mathrm{P}_{\text {cuff }}$ on VAP rate and to evaluate its cost-effectiveness. The results of the French multi-center PAV-PROTECT study ${ }^{35}$ currently being conducted will yield further insights on this issue.

\section{Polyurethane-Cuffed Tracheal Tubes}

Polyurethane is 40 -fold thinner than polyvinyl chloride (PVC), resulting in reduced channel formation between the tracheal cuff and the tracheal wall. ${ }^{36}$ Several in vitro and preliminary clinical reports suggested that polyurethane-cuffed tracheal tube might reduce microaspiration of contaminated secretions and VAP incidence. ${ }^{37-39}$ In addition, 2 before/after studies suggested beneficial effects of these tubes on microaspiration and VAP incidence. ${ }^{40,41}$

Lucangelo et al ${ }^{42}$ randomized 40 critically ill subjects to be intubated with polyurethane or PVC cuffed tracheal tubes. The effect of a 5-cm $\mathrm{H}_{2} \mathrm{O}$ PEEP aspiration of blue dye was also evaluated. Polyurethane and PEEP both significantly protected subjects from aspiration of blue dye.

Poelaert et $\mathrm{al}^{43}$ performed a randomized controlled openlabel study to determine the impact of a polyurethanecuffed tracheal tube on the postoperative pneumonia rate. One hundred thirty-four subjects scheduled for cardiac surgery were included, and the rate of early postoperative pneumonia was significantly lower in the polyurethane group than in the PVC group ( $23 \%$ vs $42 \%, P=.03$ ). Two other randomized controlled trials reported reduced incidence of VAP in subjects intubated with polyurethanecuffed tracheal tubes compared with PVC-cuffed tracheal tubes. ${ }^{44,45}$ However, in these studies, SSD was only used in the intervention group, resulting in difficult interpretation of the results. In fact, whether the reduced rate of VAP in the intervention group is related to the polyurethane cuff or to SSD is unknown.

The TOP-CUFF study ${ }^{46}$ carefully evaluated the impact of polyurethane vs PVC cuff/tapered vs cylindrical shape tubes. Six hundred twenty-one subjects were randomized to receive cylindrical-PVC, cylindrical-polyurethane, tapered-PVC, or tapered-polyurethane tracheal tubes. The percentage of subjects with tracheobronchial colonization at day 3 , which was the primary objective of the study, was similar $(P=.55)$ in the 4 study groups $(66,61,67$, and $62 \%$, respectively). Similarly, no significant difference was found in time to VAP occurrence in different 
study groups ( $\log$ rank, $P=.28$ ). Some study limitations should be outlined. First, a large proportion of study subjects received antibiotic treatment during their ICU stay, which might have been a confounder regarding the results on colonization rate. Second, tracheobronchial colonization is probably not an excellent marker for microaspiration, because it could also result from exogenous contamination.

One drawback of the use of polyurethane-cuffed tracheal tubes is the difficult measurement of $\mathrm{P}_{\text {cuff }}$ in patients intubated with these tubes. Because of physical and chemical features of polyurethane, condensation is generated by this material, resulting in the presence of water in the pilot balloon, precluding any accurate $\mathrm{P}_{\text {cuff }}$ measurement. This phenomenon was described by in vitro and clinical studies. ${ }^{47,48}$

\section{Tapered-Cuff Tracheal Tubes}

Tracheal cuff shape might play an important role in the occurrence of microaspiration in intubated patients. ${ }^{10,49}$ Previous bench studies suggested a beneficial effect of tapered-cuff tracheal tubes in reducing leakage around the cuff, by providing a permanent sealing zone between the cuff and the tracheal wall. ${ }^{38,50}$ An animal study also reported significant reduction of leakage using PVC tapered cuffs versus cylindrical cuffs. ${ }^{51}$ However, other in vitro and animal studies did not confirm these findings. ${ }^{52}$ Clinical studies have reported conflicting results on the impact of the tapered-cuff tracheal tube on microaspiration, tracheobronchial colonization, early-onset postoperative pneumonia, and VAP. 40,46,48,53-55

Three randomized controlled trials ${ }^{46,54,56}$ evaluated the impact of tapered-shaped tracheal cuff on microaspiration, tracheobronchial colonization, early postoperative pneumonia, and VAP in critically ill subjects. In the abovediscussed TOPCUFF trial, ${ }^{46}$ no significant impact was found of tapered-cuff shape on tracheobronchial colonization or VAP incidence. In the single-center randomized controlled TETRIS study, Monsel et al ${ }^{54}$ aimed at evaluating the impact of tapered-cuff, compared with standardcuff tracheal tube, on postoperative pneumonia and microaspiration. No significant impact of this intervention was found on primary or secondary outcomes. As acknowledged by the authors, the single-center design and inclusion of only subjects after major vascular surgery preclude definite conclusions. In addition, pepsin and $\alpha$ amylase were only measured at 2 time points. Our group performed a multi-center cluster crossover randomized controlled study to determine the impact of a tapered-cuff tracheal tube compared with a standard (barrel)-cuff tracheal tube on abundant microaspiration of gastric contents. ${ }^{56}$ Threehundred twenty-six subjects were included (162 and 164 in the tapered- and standard-cuff groups, respectively).
The percentage of subjects with abundant microaspiration of gastric contents was 53.5\% in the tapered-cuff and 51.0\% in the standard-cuff group (odds ratio $1.14,95 \%$ CI 0.72 1.82). The percentage of subjects with tracheobronchial colonization was significantly lower in the tapered-cuff compared with the standard-cuff group. However, no significant difference was found in other secondary outcomes, including abundant microaspiration of oropharyngeal secretions, ventilator-associated events, and VAP, between the 2 groups.

The results of these studies suggest that the tapered cuff should probably not be used to prevent VAP in critically ill patients. To our knowledge, no data are available on the safety or the cost-effectiveness of tapered-cuff tracheal tubes. Shin et $\mathrm{al}^{57}$ showed that in anesthetized subjects receiving $\mathrm{N}_{2} \mathrm{O}, \mathrm{P}_{\text {cuff }}$ was significantly lower in subjects with tapered-cuff compared with those with standard-cuff tracheal tubes. However, the number of included subjects was small, $\mathrm{P}_{\text {cuff }}$ was not continuously measured, and clinical signs of tracheal lesions were similar in the 2 groups. In addition, 2 other studies using continuous measurement of $\mathrm{P}_{\text {cuff }}$ reported different results. Monsel et al ${ }^{54}$ continuously measured $\mathrm{P}_{\text {cuff }}$ for $5 \mathrm{~h}$ in 109 subjects. The percentage of time spent with $\mathrm{P}_{\text {cuff }}>30 \mathrm{~cm} \mathrm{H}_{2} \mathrm{O}$ and the coefficient of $\mathrm{P}_{\text {cuff }}$ variation were significantly higher in subjects intubated with the tapered cuff, compared with those intubated with the standard cuff. Our group continuously recorded $\mathrm{P}_{\text {cuff }}$ for $24 \mathrm{~h}$ in 76 subjects intubated with different cuff shape and material. ${ }^{40}$ Although no significant difference was found in the percentage of time spent with $\mathrm{P}_{\text {cuff }}>30 \mathrm{~cm} \mathrm{H}_{2} \mathrm{O}$, the coefficient of $\mathrm{P}_{\text {cuff }}$ variation was significantly higher in subjects intubated with the tapered cuff, compared with those intubated with other cuff shape.

\section{Silver-Coated Tracheal Tubes}

Biofilm formation around the tracheal tube is one of the mechanisms for VAP occurrence and recurrence. Clinical studies showed a close relationship between bacteria isolated in the biofilm and those responsible for $\mathrm{VAP}^{58}$ and suggested that biofilm stands as a pathogenic mechanism for microbial persistence and impaired response to treatment in VAP. 59

In vitro, animal, and preliminary clinical studies have suggested a beneficial effect of silver-coated tracheal tubes in reducing biofilm formation and lower respiratory tract colonization. ${ }^{60-62}$ A large multi-center randomized controlled study was performed to determine the impact of silver-coated tracheal tubes on VAP incidence. ${ }^{63}$ Among subjects intubated for $\geq 24 \mathrm{~h}$, rates of microbiologically confirmed VAP were significantly lower in the group receiving the silver-coated tube than in the group receiving the uncoated tube $(4.8 \%$ vs $7.5 \%, P=.030)$. The silver- 
coated tracheal tube was associated with delayed occurrence of $\operatorname{VAP}(P=.005)$. However, the beneficial effect of this measure was only obvious during the first $10 \mathrm{~d}$ of mechanical ventilation. Further, a significantly higher rate of COPD was reported in the control group, resulting in difficult interpretation of the results. COPD was repeatedly identified as a risk factor for VAP. ${ }^{9}$ Further large randomized controlled trials are needed to determine the impact of silver-coated tracheal tubes on VAP incidence. Using Monte Carlo simulations and sensitivity analyses, Shorr et $\mathrm{al}^{64}$ reported that estimates were most sensitive to assumptions regarding VAP cost and relative risk reduction with silver-coated endotracheal tubes, compared with standard tubes. Nonetheless, in multivariate sensitivity analyses, the silver-coated endotracheal tubes yielded persistent savings (95\% CI $\$ 9,630$ to $\$ 16,356$ ) per case of VAP prevented.

Other preventive measures aimed at removing biofilm to reduce VAP incidence are currently under investigation. A recent randomized controlled study performed in 74 subjects suggested beneficial effects of a new device (endOclear) in removing biofilm from tracheal tubes. ${ }^{65}$ However, further large studies are needed to evaluate its efficacy in preventing VAP.

\section{Low-Volume Low-Pressure Cuffs}

The use of tracheal tubes with low-volume low-pressure cuff was suggested to reduce microaspiration and VAP. A recent in vitro study confirmed earlier findings regarding the efficiency of this tracheal tube in reducing leakage around the cuff, compared with other available tracheal tubes. ${ }^{66}$ Several small clinical trials also reported improved sealing and lower VAP rates in subjects intubated with these tubes. ${ }^{67,68}$ The PneuX system (Intavent Direct, Berkshire, UK) incorporates several strategies to minimize the aspiration of oropharyngeal secretions. These include a securing flange, a low-volume low-pressure cuff, multiple SSD ports, a tracheal seal monitor, and a coated tube lumen. Doyle et al ${ }^{67}$ tested this tracheal tube in a retrospective study performed in 53 subjects. Nine subjects $(17 \%)$ were initially intubated with the PneuX and 44 subjects (83\%) underwent elective exchange to the PneuX. There were no episodes of VAP while the PneuX was in situ.

In 2015, a randomized controlled single-center open label study was performed to determine the impact of the PneuX on postoperative pneumonia rate in high-risk patients undergoing cardiac surgery. ${ }^{69}$ Two-hundred forty subjects were included, and the rate of pneumonia was significantly lower in the PneuX group compared with the control group (10.8\% vs $21 \%, P=.030)$. However, the single-center design and the very short duration of mechanical ventilation in study subjects $(15 \mathrm{~h}$ vs $13 \mathrm{~h}$ in the PneuX and standard tube groups, respectively) preclude any definite conclusions regarding the effectiveness of us- ing the PneuX tube for VAP prevention. In addition, it is very difficult, if not impossible, to determine which of the tested measures (ie, low-volume low-pressure, continuous control of $\mathrm{P}_{\text {cuff }}$, or SSD) was responsible for the positive results obtained on the postoperative pneumonia rate.

\section{Summary}

SSD is efficient in VAP prevention and should probably be used in all patients with expected duration of mechanical ventilation $>48 \mathrm{~h}$. Tapered-cuff tracheal tubes are not useful to prevent VAP and should probably not be used in critically ill patients. Additional data on safety and costeffectiveness are needed. Further studies are required to confirm the promising effects of continuous control of $\mathrm{P}_{\text {cuff }}$, polyurethane-cuffed, silver-coated, and low-volume low-pressure tracheal tubes. The impact of different preventive measures on antibiotic consumption should also be evaluated.

\section{REFERENCES}

1. Dudeck MA, Horan TC, Peterson KD, Allen-Bridson K, Morrell GC, Pollock DA, Edwards JR. National Healthcare Safety Network (NHSN) report, data summary for 2009, device-associated module. Am J Infect Control 2011;39(5):349-367.

2. European Center for Disease Prevention and Control. Annual Epidemiological Report 2011: reporting on 2009 surveillance data and 2010 epidemic intelligence data. Stockholm: ECDC; 2011. http:// www.ecdc.europa.eu. Accessed April 10, 2017.

3. Rosenthal VD, Maki DG, Mehta Y, Leblebicioglu H, Memish ZA, Al-Mousa $\mathrm{HH}$, et al. International Nosocomial Infection Control Consortium (INICC) report, data summary of 43 countries for 20072012: device-associated module. Am J Infect Control 2014;42(9): 942-956.

4. Metersky ML, Wang Y, Klompas M, Eckenrode S, Bakullari A, Eldridge N. Trend in ventilator-associated pneumonia rates between 2005 and 2013. JAMA 2016;316(22):2427-2429.

5. Melsen WG, Rovers MM, Groenwold RHH, Bergmans DCJJ, Camus C, Bauer TT, et al. Attributable mortality of ventilator-associated pneumonia: a meta-analysis of individual patient data from randomised prevention studies. Lancet Infect Dis 2013;13(8):665671.

6. Six S, Jaffal K, Ledoux G, Jaillette E, Wallet F, Nseir S. Hyperoxemia as a risk factor for ventilator-associated pneumonia. Crit Care 2016;20(1):195.

7. Nseir S, Zerimech F, Jaillette E, Artru F, Balduyck M. Microaspiration in intubated critically ill patients: diagnosis and prevention. Infect Disord Drug Targets 2011;11(4):413-423.

8. Craven DE, Hudcova J, Rashid J. Antibiotic therapy for ventilatorassociated tracheobronchitis : a standard of care to reduce pneumonia , morbidity and costs? Curr Opin Pulm Med 2015;21(3):250-259.

9. Rouzé A, Cottereau A, Nseir S. Chronic obstructive pulmonary disease and the risk for ventilator-associated pneumonia. Curr Opin Crit Care 2014;20(5):525-531.

10. Haas CF, Eakin RM, Konkle MA, Blank R. Endotracheal tubes: old and new. Respir Care 2014;59(6):933-952; discussion 952-955.

11. Caroff DA, Li L, Muscedere J, Klompas M. Subglottic secretion drainage and objective outcomes: a systematic review and metaanalysis. Crit Care Med 2016;44(4):830-840. 


\section{Tracheal Tube Design and VAP}

12. Mao Z, Gao L, Wang G, Liu C, Zhao Y, Gu W, et al. Subglottic secretion suction for preventing ventilator-associated pneumonia: an updated meta-analysis and trial sequential analysis. Crit Care 2016; 20(1):353.

13. Damas P, Frippiat F, Ancion A, Canivet JL, Lambermont B, Layios $\mathrm{N}$, et al. Prevention of ventilator-associated pneumonia and ventilator-associated conditions. Crit Care Med 2015;43(1):22-30.

14. Shorr AF, O'Malley PG. Continuous subglottic suctioning for the prevention of ventilator-associated pneumonia: potential economic implications. Chest 2001;119(1):228-235.

15. Hallais C, Merle V, Guitard PG, Moreau A, Josset V, Thillard D, et al. Is continuous subglottic suctioning cost-effective for the prevention of ventilator-associated pneumonia? Infect Control Hosp Epidemiol 2011;32(2):131-135.

16. Branch-Elliman W, Wright SB, Howell MD. Determining the ideal strategy for ventilator-associated pneumonia prevention: cost-benefit analysis. Am J Respir Crit Care Med 2015;192(1):57-63.

17. Berra L, De Marchi L, Panigada M, Yu ZX, Baccarelli A, Kolobow T. Evaluation of continuous aspiration of subglottic secretion in an in vivo study. Crit Care Med 2004;32(10):2071-2078.

18. Suys E, Nieboer K, Stiers W, De Regt J, Huyghens L, Spapen H. Intermittent subglottic secretion drainage may cause tracheal damage in patients with few oropharyngeal secretions. Intensive Crit Care Nurs 2013;29(6):317-320.

19. Lacherade JC, De Jonghe B, Guezennec P, Debbat K, Hayon J, Monsel A, et al. Intermittent subglottic secretion drainage and ventilator-associated pneumonia: a multicenter trial. Am J Respir Crit Care Med 2010;182(7):910-917.

20. Klompas M, Branson R, Eichenwald EC, Greene LR, Howell MD, Lee G, et al. Strategies to prevent ventilator-associated pneumonia in acute care hospitals: 2014 update. Infect Control Hosp Epidemiol 2014;35(8):915-936.

21. Li Bassi G, Senussi T, Idone F, Aguilera Xiol E, Travierso E, Chiurazzi $\mathrm{C}$, et al. Preliminary evaluation of a novel strategy to aspirate subglottic secretions following intubation with standard endotracheal tubes. Intensive Care Med Exp 2016;3(Suppl 1):A663, P140.

22. Deem S, Yanez D, Sissons-Ross L, Broeckel JAE, Daniel S, Treggiari M. Randomized pilot trial of two modified endotracheal tubes to prevent ventilator-associated pneumonia. Ann Am Thorac Soc 2016;13(1):72-80.

23. Vallés J, Artigas A, Rello J, Bonsoms N, Fontanals D, Blanch L, et al. Continuous aspiration of subglottic secretions in preventing ventilator-associated pneumonia. Ann Intern Med 1995;122(3):179186.

24. Nseir S, Brisson H, Marquette CH, Chaud P, Di Pompeo C, Diarra $\mathrm{M}$, Durocher A. Variations in endotracheal cuff pressure in intubated critically ill patients: prevalence and risk factors. Eur J Anaesthesiol 2009;26(3):229-234.

25. Rouzé A, Nseir S. Continuous control of tracheal cuff pressure for the prevention of ventilator-associated pneumonia in critically ill patients: where is the evidence? Curr Opin Crit Care 2013;19(5): 440-447.

26. Duguet A, D’Amico L, Biondi G, Prodanovic H, Gonzalez-Bermejo J, Similowski T. Control of tracheal cuff pressure: a pilot study using a pneumatic device. Intensive Care Med 2007;33(1):128-132.

27. Weiss M, Doell C, Koepfer N, Madjdpour C, Woitzek K, Bernet V. Rapid pressure compensation by automated cuff pressure controllers worsens sealing in tracheal tubes. Br J Anaesth 2009;102(2):273278.

28. Chenelle CT, Oto J, Sulemanji D, Fisher DF, Kacmarek RM. Evaluation of an automated endotracheal tube cuff controller during simulated mechanical ventilation. Respir Care 2015;60(2):183-190.

29. Nseir S, Rodriguez A, Saludes P, De Jonckheere J, Valles J, Artigas A, Martin-Loeches I. Efficiency of a mechanical device in control- ling tracheal cuff pressure in intubated critically ill patients: a randomized controlled study. Ann Intensive Care 2015;5(1):54.

30. Nseir S, Zerimech F, Fournier C, Lubret R, Ramon P, Durocher A, Balduyck M. Continuous control of tracheal cuff pressure and microaspiration of gastric contents in critically ill patients. Am J Respir Crit Care Med 2011;184(9):1041-1047.

31. Rouzé A, De Jonckheere J, Zerimech F, Labreuche J, ParmentierDecrucq E, Voisin B, et al. Efficiency of an electronic device in controlling tracheal cuff pressure in critically ill patients: a randomized controlled crossover study. Ann Intensive Care 2016;6(1):93.

32. Valencia M, Ferrer M, Farre R, Navajas D, Badia JR, Nicolas JM, Torres A. Automatic control of tracheal tube cuff pressure in ventilated patients in semirecumbent position: a randomized trial. Crit Care Med 2007;35(6):1543-1549.

33. Lorente L, Lecuona M, Jiménez A, Lorenzo L, Roca I, Cabrera J, et al. Continuous endotracheal tube cuff pressure control system protects against ventilator-associated pneumonia. Crit Care 2014;18(2): R77.

34. Nseir S, Lorente L, Ferrer M, Rouzé A, Gonzalez O, Bassi GL, et al. Continuous control of tracheal cuff pressure for VAP prevention: a collaborative meta-analysis of individual participant data. Ann Intensive Care 2015;5(1):43.

35. Simple mechanical device to control pressure in the balloon of the endotracheal tube to prevent ventilator-acquired pneumonia. ClinicalTrials.gov. https://clinicaltrials.gov/ct2/show/NCT02514655. Accessed April 102017.

36. Blot SI, Rello J, Koulenti D. The value of polyurethane-cuffed endotracheal tubes to reduce microaspiration and intubation-related pneumonia: a systematic review of laboratory and clinical studies. Crit Care 2016;20(1):203-

37. Dullenkopf A, Gerber A, Weiss M. Fluid leakage past tracheal tube cuffs: evaluation of the new Microcuff endotracheal tube. Intensive Care Med 2003;29(10):1849-1853.

38. Dave MH, Frotzler A, Spielmann N, Madjdpour C, Weiss M. Effect of tracheal tube cuff shape on fluid leakage across the cuff: an in vitro study. Br J Anaesth 2010;105(4):538-543.

39. Ouanes I, Lyazidi A, Danin PE, Rana N, Di Bari A, Abroug F, et al. Mechanical influences on fluid leakage past the tracheal tube cuff in a benchtop model. Intensive Care Med 2011;37(4):695-700.

40. Nseir S, Zerimech F, De Jonckheere J, Alves I, Balduyck M, Durocher A. Impact of polyurethane on variations in tracheal cuff pressure in critically ill patients: a prospective observational study. Intensive Care Med 2010;36(7):1156-1163.

41. Miller MA, Arndt JL, Konkle MA, Chenoweth CE, Iwashyna TJ, Flaherty KR, Hyzy RC. A polyurethane cuffed endotracheal tube is associated with decreased rates of ventilator-associated pneumonia. J Crit Care 2011;26(3):280-286.

42. Lucangelo U, Zin WA, Antonaglia V, Petrucci L, Viviani M, Buscema $\mathrm{G}$, et al. Effect of positive expiratory pressure and type of tracheal cuff on the incidence of aspiration in mechanically ventilated patients in an intensive care unit. Crit Care Med 2008;36(2):409-413.

43. Poelaert J, Depuydt P, De Wolf A, Van de Velde S, Herck I, Blot S. Polyurethane cuffed endotracheal tubes to prevent early postoperative pneumonia after cardiac surgery: a pilot study. J Thorac Cardiovasc Surg 2008;135(4):771-776.

44. Lorente L, Lecuona M, Jiménez A, Mora ML, Sierra A. Influence of an endotracheal tube with polyurethane cuff and subglottic secretion drainage on pneumonia. Am J Respir Crit Care Med 2007;176(11): 1079-1083.

45. Mahmoodpoor A, Hamishehkar H, Hamidi M, Shadvar K, Sanaie S, Golzari SE, et al. A prospective randomized trial of tapered-cuff endotracheal tubes with intermittent subglottic suctioning in preventing ventilator-associated pneumonia in critically ill patients. J Crit Care 2017;38:152-156. 


\section{Tracheal Tube Design and VAP}

46. Philippart F, Gaudry S, Quinquis L, Lau N, Ouanes I, Touati S, et al. TOP-Cuff Study Group: randomized intubation with polyurethane or conical cuffs to prevent pneumonia in ventilated patients. Am J Respir Crit Care Med 2015;191(6):637-645.

47. Spapen H, Moeyersons W, Stiers W, Desmet G, Suys E. Condensation of humidified air in the inflation line of a polyurethane cuff precludes correct continuous pressure monitoring during mechanical ventilation. J Anesth 2014;28(6):949-951.

48. Jaillette E, Zerimech F, De Jonckheere J, Makris D, Balduyck M, Durocher A, et al. Efficiency of a pneumatic device in controlling cuff pressure of polyurethane-cuffed tracheal tubes: a randomized controlled study. BMC Anesthesiol 2013;13(1):50-.

49. Branson RD, Hess DR. Lost in translation: failure of tracheal tube modifications to impact ventilator-associated pneumonia. Am J Respir Crit Care Med 2015;191(6):606-608.

50. Madjdpour C, Mauch J, Dave MH, Spielmann N, Weiss M. Comparison of air-sealing characteristics of tapered-vs. cylindrical-shaped high-volume, low-pressure tube cuffs. Acta Anaesthesiol Scand 2012; 56(2):230-235.

51. Lichtenthal P, Borg U, Maul D. Do endotracheal tubes prevent microaspiration? Crit Care 2010;14(Suppl 1):P229.

52. Li Bassi G, Luque N, Martí JD, Aguilera Xiol E, Di Pasquale M, Giunta V, et al. Endotracheal tubes for critically ill patients. Chest 2015; 147(5):1327-1335.

53. D'Haese J, De Keukeleire T, Remory I, Van Rompaey K, Umbrain V, Poelaert J. Assessment of intraoperative microaspiration: does a modified cuff shape improve sealing? Acta Anaesthesiol Scand 2013; 57(7):873-880.

54. Monsel A, Lu Q, Le Corre M, Brisson H, Arbelot C, Vezinet C, et al. Tapered-cuff endotracheal tube does not prevent early postoperative pneumonia compared with spherical-cuff endotracheal tube after major vascular surgery: a randomized controlled trial. Anesthesiology 2016;124(5):1041-1052.

55. Bowton DL, Hite RD, Martin RS, Sherertz R. The impact of hospital-wide use of a tapered-cuff endotracheal tube on the incidence of ventilator-associated pneumonia. Respir Care 2013;58(10):15821587.

56. Jaillette E, Girault C, Brunin G, Zerimech F, Chiche A, BroucqsaultDedrie $\mathrm{C}$, et al. Impact of tracheal cuff shape on microaspiration of gastric contents in intubated critically ill patients: study protocol for a randomized controlled trial. Intensive Care Med. doi: 10.1186/ s13063-015-0955-z.

57. Shin HW, Kim DH, Yoo HS, Lee DK, Yoo YD, Lim CH. Changes in cuff pressure and position of cylindrical-cuff and tapered-cuff tracheal tubes during laparoscopic abdominal surgery. J Int Med Res 2015;43(4):544-554.
58. Adair CG, Gorman SP, Feron BM, Byers LM, Jones DS, Goldsmith $\mathrm{CE}$, et al. Implications of endotracheal tube biofilm for ventilatorassociated pneumonia. Intensive Care Med 1999;25(10):1072-1076.

59. Gil-Perotin S, Ramirez P, Marti V, Sahuquillo JM, Gonzalez E, Calleja I, et al. Implications of endotracheal tube biofilm in ventilator-associated pneumonia response: a state of concept. Crit Care 2012;16(3):R93.

60. Olson ME, Harmon BG, Kollef MH. Silver-coated endotracheal tubes associated with reduced bacterial burden in the lungs of mechanically ventilated dogs. Chest 2002;121(3):863-870.

61. Rello J, Kollef M, Diaz E, Sandiumenge A, del Castillo Y, Corbella $\mathrm{X}$, Zachskorn R. Reduced burden of bacterial airway colonization with a novel silver-coated endotracheal tube in a randomized multiple-center feasibility study. Crit Care Med 2006;34(11):2766-2772.

62. Rello J, Afessa B, Anzueto A, Arroliga AC, Olson ME, Restrepo MI, et al. Activity of a silver-coated endotracheal tube in preclinical models of ventilator-associated pneumonia and a study after extubation. Crit Care Med 2010;38(4):1135-1140.

63. Kollef MH, Afessa B, Anzueto A, Veremakis C, Kerr KM, Margolis $\mathrm{BD}$, et al. Silver-coated endotracheal tubes and incidence of ventilator-associated pneumonia: the NASCENT randomized trial. JAMA 2008;300(7):805-813.

64. Shorr AF, Zilberberg MD, Kollef M. Cost-effectiveness analysis of a silver-coated endotracheal tube to reduce the incidence of ventilator-associated pneumonia. Infect Control Hosp Epidemiol 2009;30(8): 759-763.

65. Pinciroli R, Mietto C, Piriyapatsom A, Chenelle CT, Thomas JG, Pirrone M, et al. Endotracheal tubes cleaned with a novel mechanism for secretion removal: a randomized controlled clinical study. Respir Care 2016;61(11):1431-1439.

66. Chenelle CT, Itagaki T, Fisher DF, Berra L, Kacmarek RM. Performance of the PneuX System: a bench study comparison with 4 other endotracheal tube cuffs. Respir Care 2017;62(1):102-112.

67. Doyle A, Fletcher A, Carter J, Blunt M, Young P. The incidence of ventilator-associated pneumonia using the PneuX System with or without elective endotracheal tube exchange: a pilot study. BMC Res Notes 2011;4:92.

68. Young PJ, Pakeerathan S, Blunt MC, Subramanya S. A low-volume, low-pressure tracheal tube cuff reduces pulmonary aspiration. Crit Care Med 2006;34(3):632-639.

69. Gopal S, Luckraz H, Giri R, Nevill A, Muhammed I, Reid M, et al. Significant reduction in ventilator-associated pneumonia with the Venner-PneuX System in high-risk patients undergoing cardiac surgery: the low ventilator-associated-pneumonia study. Eur J Cardiothorac Surg 2015;47(3):e92-e96. 